\title{
Features of Martensitic Transformation and Fine Structure of Intermetallic Compound $\mathrm{Ni}_{50} \mathrm{Mn}_{50}$
}

\author{
V. G. Pushin ${ }^{a, b}$, E. S. Belosludtseva ${ }^{a}$, V. A. Kazantsev ${ }^{a}$, and N. I. Kourov ${ }^{a}$ \\ ${ }^{a}$ Institute of Metal Physics, Ural Branch, Russian Academy of Sciences, Yekaterinburg, Russia \\ ${ }^{b}$ Ural Federal University, Yekaterinburg, Russia \\ e-mail:pushin@imp.uran.ru
}

\begin{abstract}
Transmission and scanning electron microscopy and X-ray and electron diffraction are used to investigate the martensitic transformation and martensitic phase structure of the $\mathrm{Ni}_{50} \mathrm{Mn}_{50}$ alloy. Its resistivity and coefficient of thermal expansion are measured over a wide temperature range.
\end{abstract}

Keywords: thermoelastic martensitic transformation, shape memory effect, intermetallic compound $\mathrm{Ni}_{50} \mathrm{Mn}_{50}$, fine structure, martensite, twins, nanotwins

DOI: $10.1134 / \mathrm{S} 2075113313040084$

\section{INTRODUCTION}

Two structural phase transformations take place under cooling in $\mathrm{Ni}-\mathrm{Mn}$ alloys near the equiatomic composition: at temperatures close to $1150-1200 \mathrm{~K}$ and 970-990 K [1, 2]. The high-temperature $\gamma$ phase has a disordered fcc lattice of the $A 1$ type with parameter $a_{\gamma}=0.3651 \mathrm{~nm}[2,3]$. The $\beta$ phase resulting from the $\gamma \rightarrow \beta$ phase transformation has a bcc $B 2$ atomically ordered lattice. The structure of the tetragonal $\theta$ phase is $L 1_{0}$ type atomically ordered [1-4]. The first transition $\gamma(A 1) \rightarrow \beta(B 2)$ is considered to be controlled by diffusion and it provides atomic ordering and crystal-lattice transformation resulting in the $B 2$ type structure formation. The second transition $\beta(B 2) \rightarrow$ $\theta\left(L 1_{0}\right)$ occurs according to a martensitic mechanism with a fairly narrow temperature hysteresis [2-5]. A similar transformation $B 2 \rightarrow L 1_{0}$ was observed in many intermetallic alloys, such as $\mathrm{Ni}-\mathrm{Al}, \mathrm{Ni}-\mathrm{Co}-\mathrm{Al}$, and $\mathrm{Ni}-\mathrm{Zn}-\mathrm{Cu}[2,6-12]$. We assume that such a transformation in these alloys has the character of a thermoelastic martensitic transformation (MT) and it should give rise to the shape memory effect in them. This study was aimed at investigating the features of phase transformation in the alloy $\mathrm{Ni}_{50} \mathrm{Mn}_{50}$ using in situ experiments on the direct study of structural and phase changes over a wide temperature range.

\section{EXPERIMENTAL}

The alloy was prepared from high-purity components: nickel NO and electrolytic manganese (99.99\%). The alloy was melted by electric arc melting in a purified argon atmosphere. The alloy was melted repeatedly (three times) for its homogenization, followed by prolonged annealing in vacuum at a temperature of $1173 \mathrm{~K}$. The ingot was cut into plates using an electric spark machine. The plates then were subjected to homogenizing annealing in the state of the $\beta(B 2)$ phase at a temperature of 1073 or $1173 \mathrm{~K}$ for $30 \mathrm{~min}$ and subsequently quenched in water or slowly cooled $(\sim 100 \mathrm{~K} / \mathrm{h})$. X-ray analysis was carried out using a DRON-3M apparatus in $\mathrm{Cu} K_{\alpha}$ radiation with the use of a monochromatized graphite crystal. The samples were examined after quenching at room temperature and upon heating to a temperature of $1100 \mathrm{~K}$ in a GPVT-2000 high-temperature chamber and subsequent cooling with X-ray patterns taken every $10 \mathrm{~K}$. Martensitic transformation temperatures were determined by the occurrence of reflections of the martensite phase and disappearance of $B 2$ austenite phase reflections. The mean-square displacements of atoms $\left\langle U_{s}^{2}\right\rangle_{\mathrm{X} \text {-ray }}$ and the Debye temperature $\theta_{D}$ as functions of the temperature were calculated following [7-15]. Electron-microscopic examination was performed using a JEM 200 CX transmission electron microscope (TEM) and a Quanta-200 scanning electron microscope (SEM) equipped with EDS and EBSD attachments at the Electron Microscopy Center of the Institute of Metal Physics of the Ural Branch of the Russian Academy of Sciences. TEM studies were conducted in light and dark fields. An electron diffraction method was used for phase identification within a selected area. A potentiometric method was applied to measure the electrical resistivity $\rho(T)$ of the alloy in the temperature range from 100 to $1170 \mathrm{~K}$ using a double bridge circuit scheme. The thermal expansion coefficient was determined with a DL 1500 RHP dilatometer in the temperature range of $300-1100 \mathrm{~K}$. The temperatures of structural transformations were established by the method of the two tangents, according to which they are defined at their intersection [11]. 
(a)

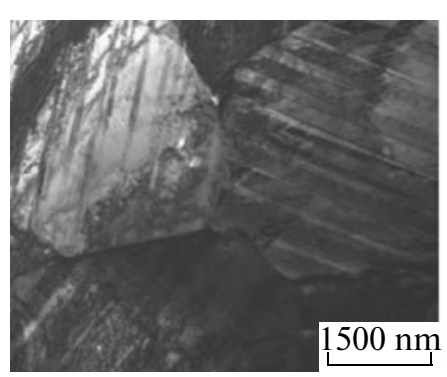

(b)

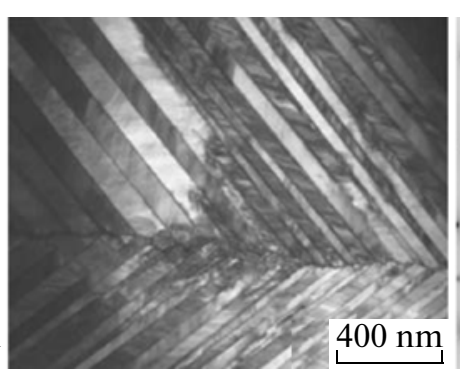

(c)

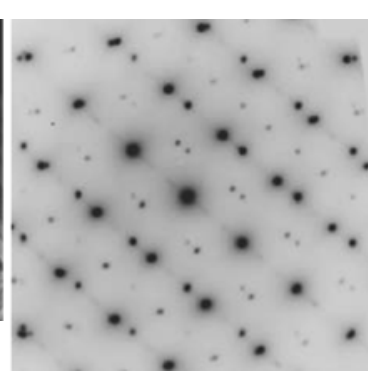

(d)

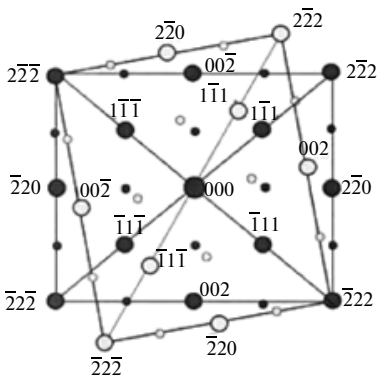

Fig. 1. (a, b) TEM bright-field images of the $L 1_{0}$ martensite structure of the $\mathrm{Ni}_{50} \mathrm{Mn}_{50}$ alloy quenched from $1073 \mathrm{~K}$. (c) Respective electron diffraction pattern (zone axis is close to $(110)_{\mathrm{fct}}$ ) and $(\mathrm{d})$ its interpretation.

(a)

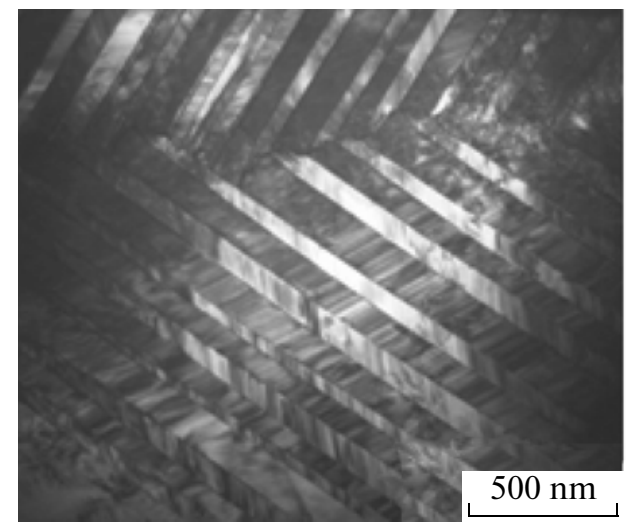

(b)

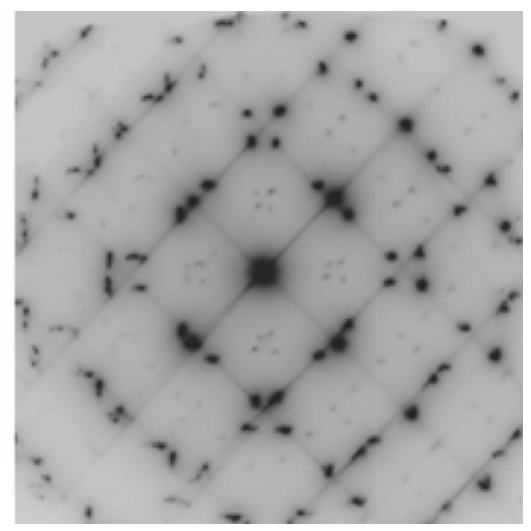

(c)

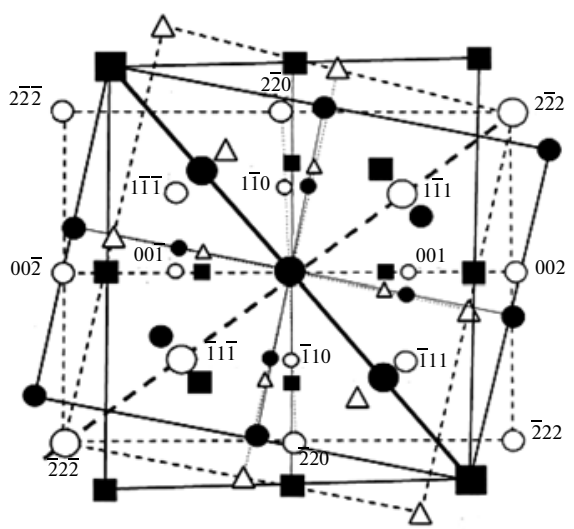

Fig. 2. (a) TEM dark-field image of the junction of two $L 1_{0}$ martensite packets of the $\mathrm{Ni}_{50} \mathrm{Mn}_{50}$ alloy quenched from $1073 \mathrm{~K}$; (b) respective electron diffraction pattern with a zone axis close to $(110)_{\mathrm{fct}}$; and (c) the scheme of its interpretation.

\section{RESULTS AND DISCUSSION}

According to $\mathrm{X}$-ray structure analysis, the $\mathrm{Ni}_{50} \mathrm{Mn}_{50}$ alloy quenched in water from 1073 or $1173 \mathrm{~K}$ for $30 \mathrm{~min}$ has a tetragonal fct lattice $L 1_{0}$ with unit cell parameters $a=0.3740 \mathrm{~nm}, c=0.3520 \mathrm{~nm}$, and $c / a=$ 0.94 .

Electron-microscopy studies at room temperature showed that the hardened $\mathrm{Ni}_{50} \mathrm{Mn}_{50}$ alloy is in a martensitic state. Figures $1 \mathrm{a}$ and $1 \mathrm{~b}$ display bright-field electron microscopic images and electron diffraction patterns of the $\mathrm{Ni}_{50} \mathrm{Mn}_{50}$ alloy after quenching from $1073 \mathrm{~K}$. These images suggest a number of features of the morphology and internal structure of martensite crystals. The martensite represents a hierarchy of packets consisting of twinned pairs of parallel plates with completely flat coherent interface boundaries between them and thin secondary inner nanotwins. A trace analysis and the interpretation of electron diffraction patterns revealed that the martensite phase crystals have an fct structure and are twinned on $(111)_{\text {fct }}$ planes. The superstructure reflections of the type 001 indicate the martensite phase to be $L 1_{0}$ atomically ordered (see Figs. 1c, 1d).

Finer grains (up to $5 \mu \mathrm{m}$ ) typically include one packet (see Fig. 1a). Grain boundaries are often rounded step shaped. In larger grains, packets are joined by interpacket boundaries, which are also not flat, although they separate coherently conjugate tetragonal $c$ domains (see Figs. 1b, 2a).

It was found by $\mathrm{X}$-ray diffraction and electron microscopy that the quenched $\mathrm{Ni}_{50} \mathrm{Mn}_{50}$ alloy is single phase at room temperature and it contains only martensite crystals with a tetragonal $L 1_{0}$ structure.

Figure 2 shows a typical dark-field image of the quenched $\mathrm{Ni}_{50} \mathrm{Mn}_{50}$ alloy. It can be seen that the martensitic crystals in packets are in a pair-twinned relationship. As a rule, a packet includes thin plates arranged almost at right angles to the adjacent plates of a neighboring packet. The interface boundary between packets with martensite crystals related by a Bain orientation within one packet and with crystals in adjacent packets is not strictly a crystallographic boundary, 


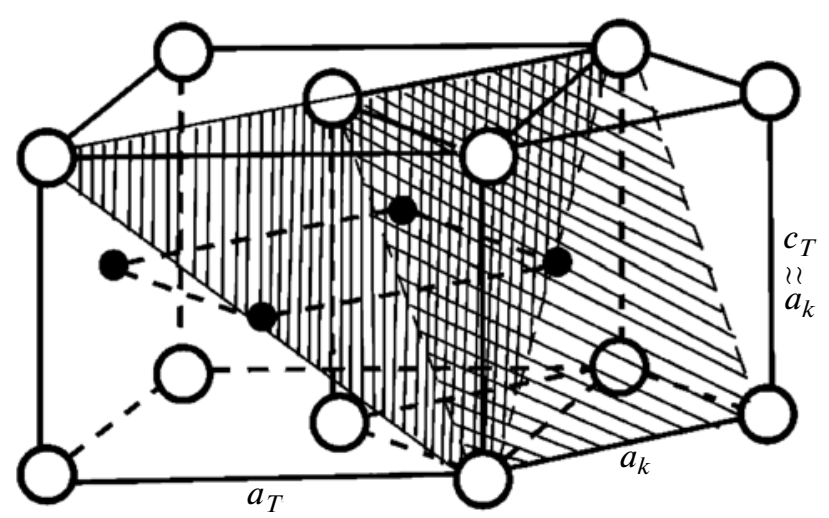

Fig. 3. Elementary cells of the $B 2$ bcc and $L 1_{0}$ crystal structures in two different views: bct and fct.
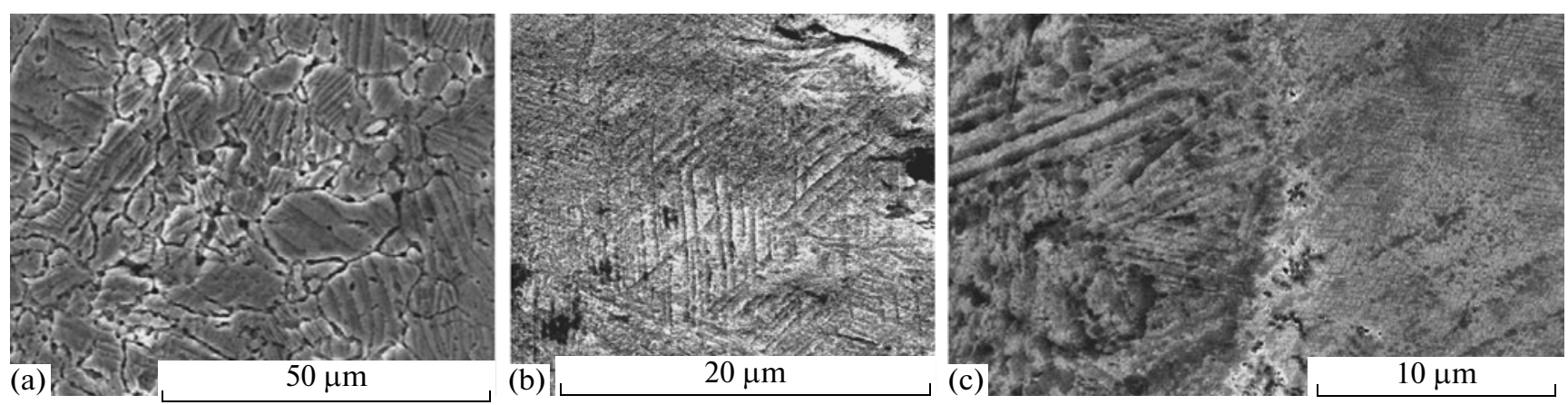

Fig. 4. Typical electron-microscopic images of $L 1_{0}$ martensite in the $\mathrm{Ni}_{50} \mathrm{Mn}_{50}$ alloy quenched from $1073 \mathrm{~K}$ in scanning reflection mode.

although it is close on average to the plane of the type $(101)_{B 2}$.

Interpretation of electron diffraction patterns showed that primary and secondary twinning occurs on planes of the same type $\{111\}_{\mathrm{fct}}$. When considering the martensite lattice in the bct basis with respect to the Bain scheme, the twinning plane is identified as $\{101\}_{\text {bct }}$ (Fig. 3). Twin packets can be formed in the structure of the quenched alloy owing to accommodative adaptive twinning that develops when cooling the martensite. The main cause of the hierarchy of twins seems to be elastic stresses arising during martensitic transformation $B 2 \rightarrow L 1_{0}$, as in $\mathrm{Ni}-\mathrm{Al}$ alloys [6-9].

The structure of the martensitic phase in an fct basis is a dense three-layered $A B C$ arrangement. Figure 3 shows the unit cells of the $B 2$ and $L 1_{0}$ crystal structures in two different views used, $B 2$ in bcc or fct and $L 1_{0}$ in bct or fct, and the $B 2 \leftrightarrow L 1_{0}$ transformation model (analog of the Bain scheme).

The TEM data are in agreement with the SEM data obtained for bulk samples (Fig. 4). It was found that martensite within the large grains is composed of crystal packets of parallel crystal-plates arranged against each other at different angles in accordance with the Bain orientational relations, but its morphology in smaller grains is usually a monopacket one.
Some refinement of the $L 1_{0}$ martensite and an increase in the number of secondary nanotwins and stacking fault packets (Fig. 5) are observed after quenching of the $\mathrm{Ni}_{50} \mathrm{Mn}_{50}$ alloy in water from higher temperatures (in particular, $1173 \mathrm{~K}$ ). This is accompanied by not only broadening of the X-ray reflections of the martensite phase but also observation of diffuse streaks along the normals to the planes of the type $\{111\}_{\text {fct }}$ in electron diffraction patterns (see Fig. 5c).

Heating to 870-900 K with subsequent holding of the alloy at that temperature seems to lead to specific thermoelastic recrystallization of the martensite and, hence, to an increase in the size and ordering of its twinned substructure (Fig. 6). When the $\mathrm{Ni}_{50} \mathrm{Mn}_{50} B 2$ alloy is cooled sufficiently slowly from high temperatures (e.g., at $100^{\circ} \mathrm{C} / \mathrm{h}$ ), it undergoes the accommodation of elastic stresses and thermal stress adaptation of martensite crystals in it under this cooling both during the $B 2 \rightarrow L 1_{0}$ MT and after its completion. These crystals form packets of micro- and nanotwins according to the same system $\{111\}\langle 11 \overline{2}\rangle_{\mathrm{fct}}$, whereas in the bct basis equivalent to twinning, according to $\{101\}\langle 10 \overline{1}\rangle_{\text {bct }}$ (Fig. 7). Well-ordered crystal-geometric conjunctions of the hierarchy of the tetragonal twinned $c$ domains are clearly visible in Figs. 6 and 7. 
Overall, however, the morphology and structure of martensite in the slowly cooled alloy is virtually identical to its structure in the quenched alloy, as well as after repeated (ten times) thermal cycling. This fact proves the thermoelastic mechanism of the MT.

On the basis of study of the diffraction data and size-orientation relationships, we can offer a crystalstructure model of the cube-tetragon MT in these alloys as twinning shuffle shifts on $\{110\}\langle 1 \overline{1} 0\rangle_{B 2}$ planes, taking into consideration the Bain distortion $B 2 \rightarrow L 1_{0}$ (Fig. 8) [6].

The analysis of temperature dependences of resistivity $\rho(T)$ gives important information about the temperature and transformation type in the study of phase transitions. This method is often used to study the structural phase transformations in alloys based on intermetallic compounds [10-12]. The measurements of $\rho(T)$ showed that the studied alloy of the $\mathrm{Ni}_{50} \mathrm{Mn}_{50}$ stoichiometric composition indeed has two phase transformations at temperatures of $1100-1150 \mathrm{~K}$ and 920-1020 K (table). The curve of $\rho(T)$ makes it clear that the first transformation under cooling is accompanied by a decrease in $\rho(T)$, but the second one is accompanied by an increase in $\rho(T)$ (Fig. 9). On the contrary, $\rho(T)$ with the characteristic thermal hysteresis under heating varies in the opposite direction. It is significant that the dependence $\rho(T)$ remains practically unchanged after ten MT thermal cycles.

The measurement of the thermal expansion coefficient is one of the important methods in the determination of the critical parameters of structural and phase changes in alloys. In many cases, the experiment yields the linear thermal expansion coefficient $\Delta L / L_{0}$ rather than the volumetric one. In the study of polycrystalline samples of a cubic system, the measurements are carried out in an arbitrary direction. When analyzing the temperature dependence of the change $\Delta L / L_{0}$, it has been found that the MT in the alloy investigated occurs at temperatures $M_{s}=960 \mathrm{~K}$, $M_{f}=940 \mathrm{~K}, A_{s}=970 \mathrm{~K}$, and $A_{f}=990 \mathrm{~K}$, and hysteresis occurs at $\sim 30 \mathrm{~K}$ (see table). The measurements shown in Fig. 10 were performed on cubic samples along three different orientations, which makes it possible to determine the volumetric transformation effect $\Delta V / V$, which is about $1.7 \%$. Comparing the data obtained from the measurements of $\rho(T)$ (see Fig. 9) and $\Delta L / L_{0}(T)$ (see Fig. 10), we can conclude that the MT temperatures found from these dependences (see table) coincide satisfactorily.

$X$-ray diffraction in situ studies have shown that the $\mathrm{Ni}_{50} \mathrm{Mn}_{50}$ alloy undergoes an $L 1_{0} \rightarrow B 2$ reverse transformation when heated from room temperature to $1100 \mathrm{~K}$. At $1100 \mathrm{~K}$, it has a $B 2$ lattice with the unit cell parameter $a_{B 2}=0.2988 \mathrm{~nm}$. There are only $B 2$ phase Bragg reflections with sharp symmetrical peaks (Fig. 11) in X-ray diffraction patterns. It was found that the intensities of Bragg reflections, including $110_{B 2}$,
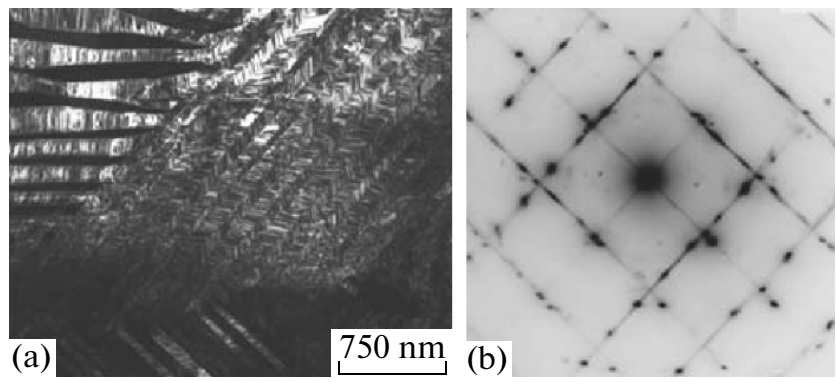

Fig. 5. (a) TEM dark-field images of the $L 1_{0}$ martensite structure of the $\mathrm{Ni}_{50} \mathrm{Mn}_{50}$ alloy quenched from $1173 \mathrm{~K}$. (b) Respective electron diffraction pattern (zone axis is close to $\left.(110)_{\mathrm{fct}}\right)$.

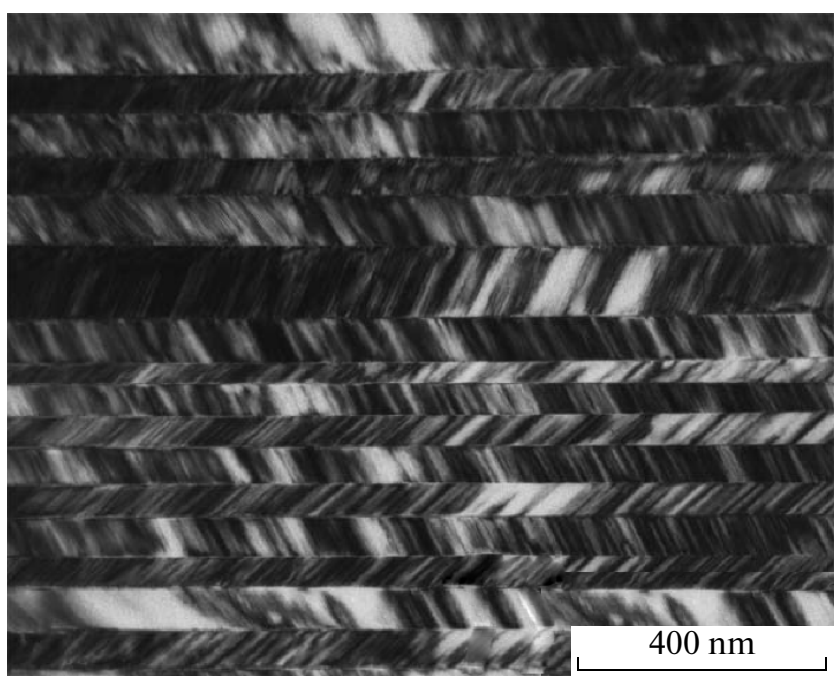

Fig. 6. TEM dark-field images of the $L 1_{0}$ martensite structure of the $\mathrm{Ni}_{50} \mathrm{Mn}_{50}$ alloy quenched from $1073 \mathrm{~K}$, heated to $870-900 \mathrm{~K}$, and cooled to room temperature.
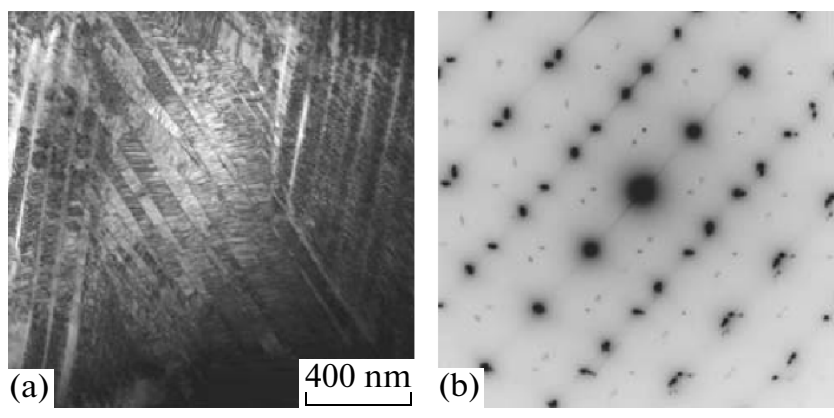

Fig. 7. (a) TEM dark-field images of the $L 1_{0}$ martensite structure of the $\mathrm{Ni}_{50} \mathrm{Mn}_{50}$ alloy after slow cooling from $1073 \mathrm{~K}\left(\sim 100^{\circ} \mathrm{C} / \mathrm{h}\right)$ and $(\mathrm{b})$ its electron diffraction pattern (zone axis is close to $(110)_{\mathrm{fct}}$ ).

decrease as the temperature of photographing is lowered to the temperature where the phase transformation starts. The asymmetric "lapping" arises from the side of $2 \theta$ high angles near the $110_{B 2}$ line and then the line splits into two: $110_{B 2}$ and $111_{L 1_{0}}$ (see Fig. 11). 


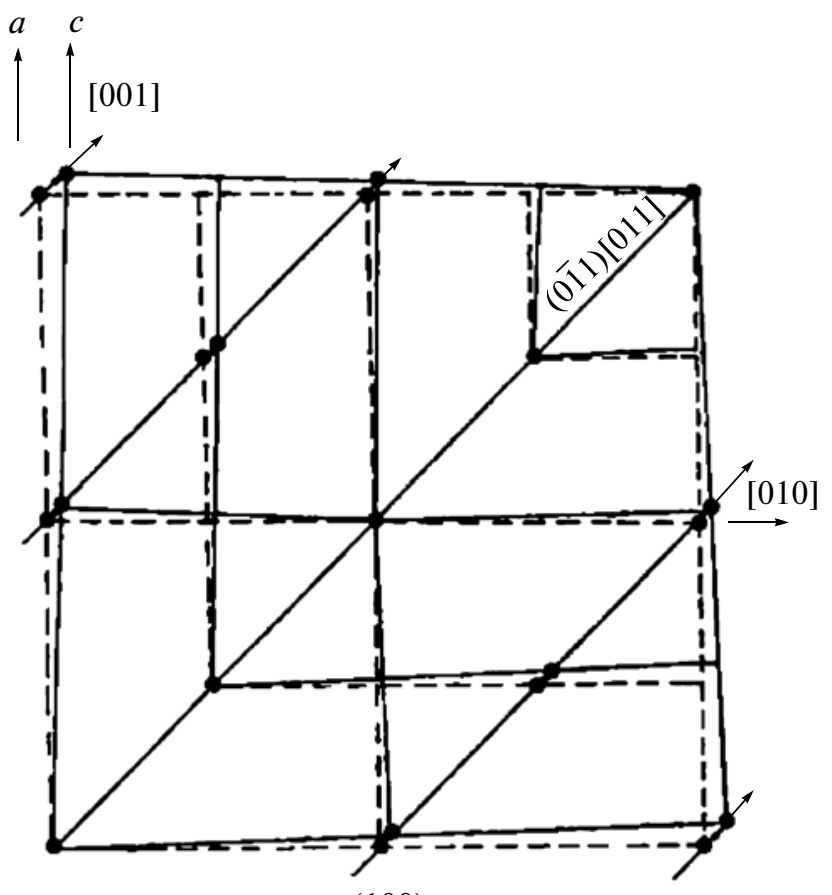

(100)

Fig. 8. Scheme of a cubic-tetragonal transformation in the $\mathrm{Ni}_{50} \mathrm{Mn}_{50}$ intermetallic compound, which is described by twinning shifts according to $(0 \overline{1} 1)[011]_{T}$ together with Bain distortion of $\{100\}\langle 100\rangle$ (plane projection (100)).

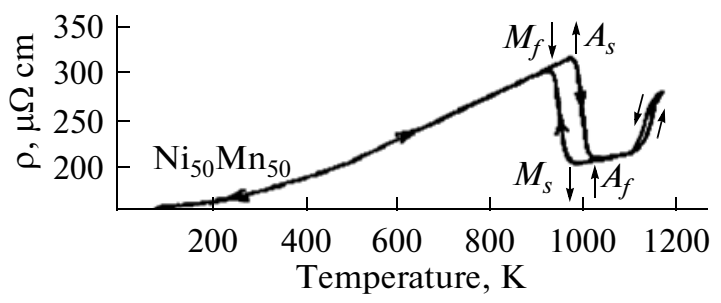

Fig. 9. Temperature dependence of the electrical resistivity $\rho(T)$ of the $\mathrm{Ni}_{50} \mathrm{Mn}_{50}$ alloy in the thermal cycle of measurements: room temperature, $R T \rightarrow$ the boiling point of liquid nitrogen $(\ln ), T_{\ln } \rightarrow R T \rightarrow 1170 \mathrm{~K} \rightarrow 870 \mathrm{~K}\left(M_{s}=970 \mathrm{~K}\right.$ $M_{f}=920 \mathrm{~K} ; A_{s}=970 \mathrm{~K} ; A_{f}=1020 \mathrm{~K}$; hysteresis $\left.\sim 50 \mathrm{~K}\right)$.

The temperature of $950 \mathrm{~K}$, at which a $111_{\text {fct }}$ line first becomes visible, can be defined as the temperature of martensitic transformation onset (see table).

Temperatures of start $\left(M_{s}, A_{s}\right)$ and finish $\left(M_{f}, A_{f}\right)$ of forward $\left(M_{s}, M_{f}\right)$ and reverse $\left(A_{s}, A_{f}\right)$ martensitic transformation and its hysteresis $(\Delta)$ in the $\mathrm{Ni}_{50} \mathrm{Mn}_{50}$ alloy

\begin{tabular}{|c|c|c|c|c|c|}
\hline \multirow[t]{2}{*}{ Research techniques } & \multicolumn{5}{|c|}{$\begin{array}{l}\text { Temperatures of martensitic } \\
\text { transformations, } K\end{array}$} \\
\hline & $M_{s}$ & $M_{f}$ & $A_{s}$ & $A_{f}$ & $\Delta$ \\
\hline Electrical resistivity & 970 & 920 & 970 & 1020 & 50 \\
\hline $\begin{array}{l}\text { Coefficient of linear } \\
\text { expansion }\end{array}$ & 960 & 940 & 970 & 990 & 30 \\
\hline $\begin{array}{l}\text { X-ray diffraction } \\
\text { analysis }\end{array}$ & 950 & 850 & - & - & - \\
\hline
\end{tabular}

The occurrence of the $111_{\text {fcc }}$ line and others indicates formation of the $L 1_{0}$ phase. Further cooling below $850 \mathrm{~K}$ led to an increase in the intensity of the $111_{L 1_{0}}$ line and the disappearance of the $110_{\mathrm{B} 2}$ line. This means that the $B 2 \rightarrow L 1_{0}$ phase transformation was completed.

The parameters $a$ and $c$ of the $L 1_{0}$ martensite phase were established at different temperatures and their temperature dependences were plotted (Fig. 12a). It was found that the value of $a$ decreased; $c$, on the contrary, increased; and their ratio $c / a$, indicating the degree of tetragonality, increased from 0.90 to 0.94 as the temperature decreased. Thus, after MT is completed, the tetragonal phase lattice shrinks along the $a$ axis and stretches along the $c$ axis as a result of cooling. At $300 \mathrm{~K}$, the $L 1_{0}$ martensite phase lattice parameters become equal to those obtained for the quenched alloy. The calculated temperature changes in the specific volumes of the $B 2$ and $L 1_{0}$ phases are shown in Fig. 12b. The $L 1_{0}$ martensite phase forms under cooling with an abrupt decrease in volume that is close to $0.75 \%$ at the point of the phase transformation onset. $V_{L 1_{0}}$ continues to decrease as the temperature is lowered.

To obtain more information about the premartensitic evolution of the $B 2$ distorted crystal lattice, we determined for the first time the Debye temperature $\theta_{D}$ and X-ray mean square atom displacements $\left\langle U_{s}^{2}\right\rangle_{\mathrm{X} \text {-ray }}$ using the temperature dependences of the 


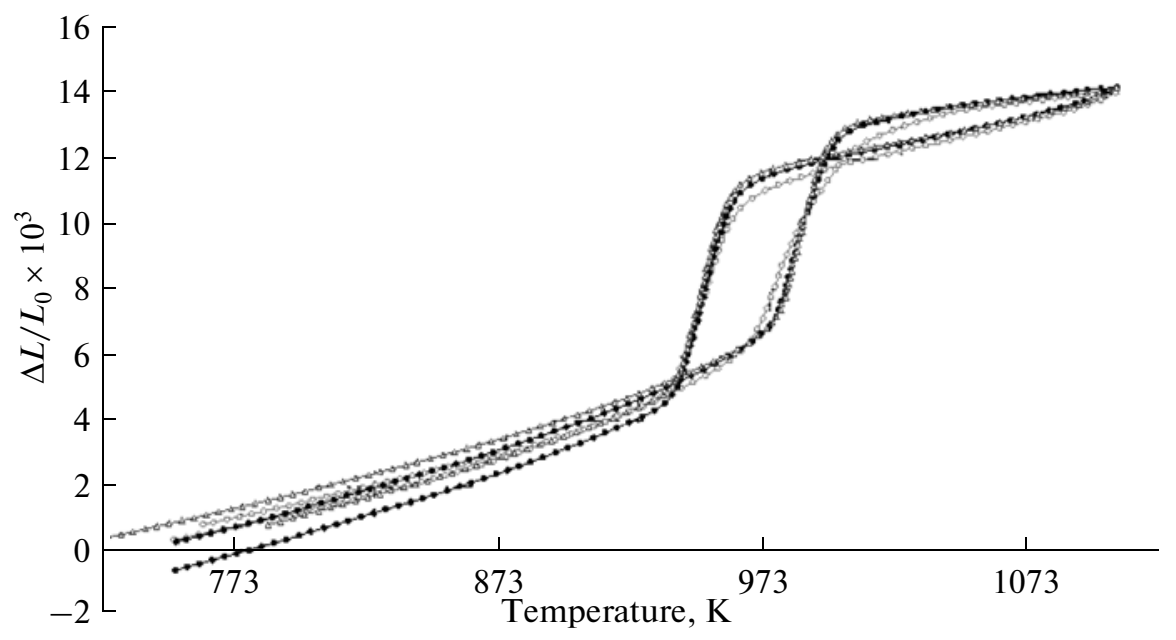

Fig. 10. Temperature dependence of the line expansion coefficient $\Delta L / L_{0}(T)$ of the $\mathrm{Ni}_{50} \mathrm{Mn}_{50}$ alloy (for three cubic samples along the $x, y$, and $z$ axes).

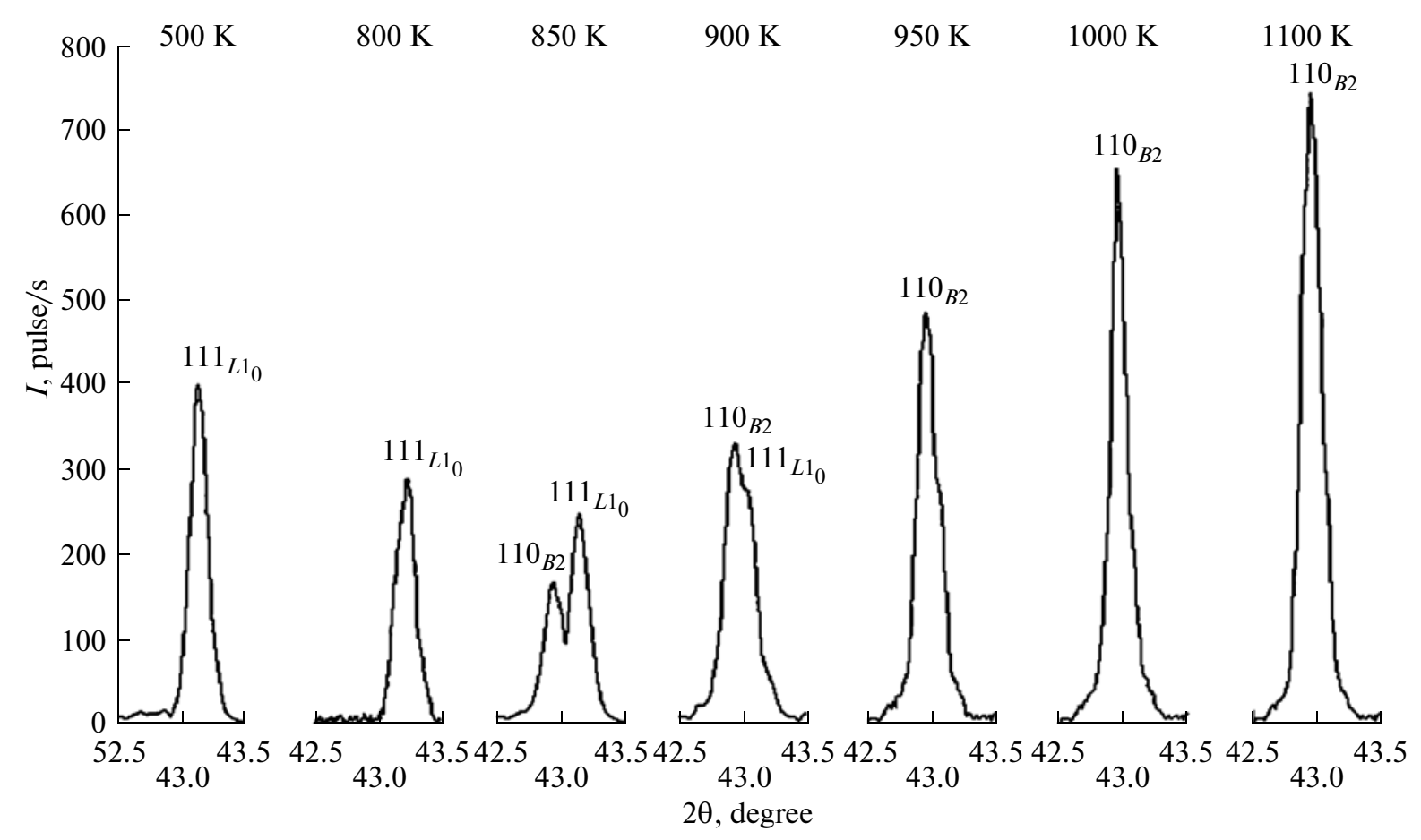

Fig. 11. Profiles of X-ray lines $110_{B 2}$ and $111_{L 1_{0}}$ of the $\mathrm{Ni}_{50} \mathrm{Mn}_{50}$ alloy at different temperatures of measurements.

intensities of Bragg B2-austenite reflections. It was established that there was an anomalous decrease in the values of the Debye temperature $\theta_{D}$ (Fig. 13a) starting from the maximum temperature of measurements $(1100 \mathrm{~K})$. This behavior of $\theta_{D}$ can be caused by a premartensitic decrease in interatomic forces in metastable alloys [7-14]. The value of $\left\langle U_{s}^{2}\right\rangle_{\mathrm{X} \text {-ray }}$, on the contrary, grows anomalously upon approaching the MT temperature (see Fig. 13b). It is known that the value of the mean square displacement of atoms is affected by both dynamic and static displacements of atoms. Their sum $\left\langle U_{s}^{2}\right\rangle_{\mathrm{X} \text {-ray }}=\left\langle U_{s}^{2}\right\rangle_{\mathrm{din}}+\left\langle U_{s}^{2}\right\rangle_{\text {stat }}$ can only be obtained from X-ray data [15]. $\left\langle U_{s}^{2}\right\rangle_{\text {din }}$ can be independently determined from elastic constants [7]. Since such data are not available, we give only the results of $\left\langle U_{s}^{2}\right\rangle_{\mathrm{X} \text {-ray }}$ calculations in our paper. In summary, we note that the thermoelastic behavior of the 


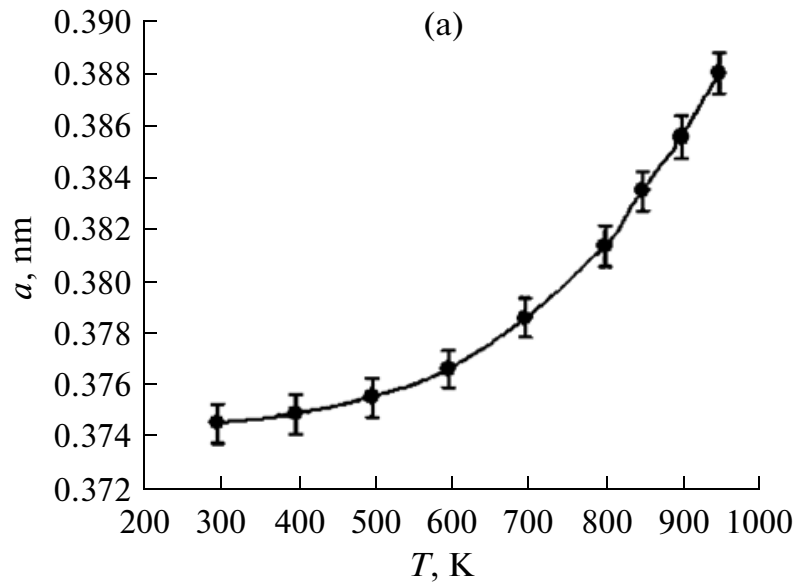

(b)
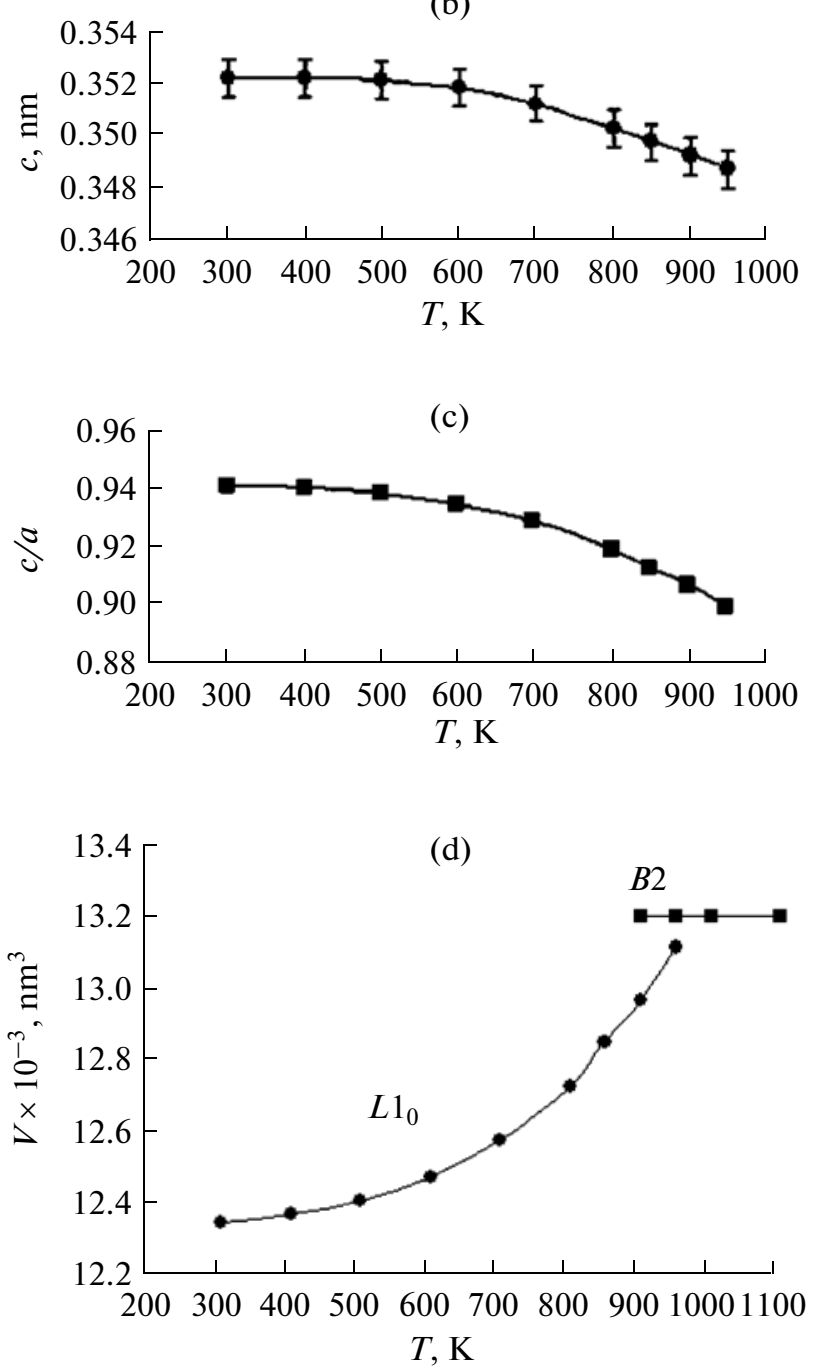

Fig. 12. Temperature dependences of (a) $L 1_{0}$ phase lattice parameters $a$ and $c$ and their ratio $c / a$ and (b) specific volumes of $V_{B 2}$ and $L 1_{0}$ lattices of the $\mathrm{Ni}_{50} \mathrm{Mn}_{50}$ alloy.

$B 2 \leftrightarrow L 1_{0}$ high-temperature MT in the alloy NiMn can result in a high-temperature shape memory effect owing to the high linear and volumetric transforma-

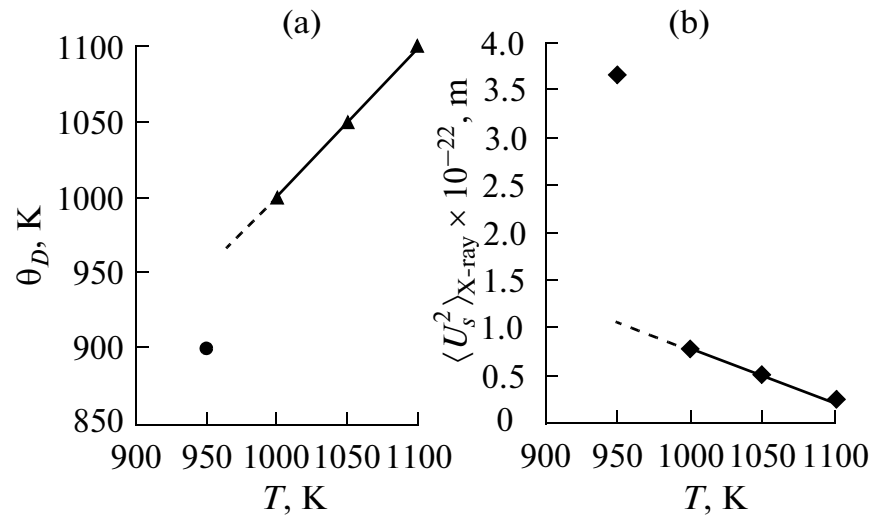

Fig. 13. High-temperature dependences of the (a) Debye temperature $\theta_{D}$ and (b) mean-square displacements of atoms $\left\langle U_{s}^{2}\right\rangle_{\mathrm{X} \text {-ray }}$ of the $\mathrm{Ni}_{50} \mathrm{Mn}_{50}$ alloy.

tion effects under conditions of high repeatability of the alloy's characteristic parameters (critical temperatures, hysteresis, the volume effect of transition, morphology, and fine structure).

\section{CONCLUSIONS}

Thus, the present study showed that the $\mathrm{Ni}_{50} \mathrm{Mn}_{50}$ alloy at $1100 \mathrm{~K}$ is a single-phase one and has the atomically ordered $B 2$ lattice with the lattice parameter $a_{B 2}=0.2988 \mathrm{~nm}$. After quenching, the alloy represents $L 1_{0}$ tetragonal martensite with parameters $a_{L 1_{0}}=$ $0.3740 \mathrm{~nm}, c_{L 1_{0}}=0.3520 \mathrm{~nm}$, and $c / a=0.94$. It undergoes the highly reversible $B 2 \leftrightarrow L 1_{0}$ MT at temperatures $M_{s}=980 \mathrm{~K}, M_{f}=920 \mathrm{~K}, A_{s}=970 \mathrm{~K}$, and $A_{f}=1020 \mathrm{~K}$. Under cooling, the transformation occurs with a reduction in the specific volume (being close to $0.75 \%$ at $M_{s}$ and $1.7 \%$ at $M_{f}$ ), which continues to drop with subsequent lowering of the temperature. Electrical resistance, dilatometry, and X-ray analysis are three independent ways used to obtained the values of the temperatures of direct and reverse MTs. The MT in the alloy was found to be of a highly reversible thermoelastic character, repeated in thermal cycling. $L 1_{0}$ martensite morphology represents the hierarchy of packets made of thin platelike and internally twinned crystals with flat habitus boundaries $\{1111\}_{L 1_{0}} / /\{101\}_{B 2}$. Twinning shift systems $\{111\}\langle 11 \overline{2}\rangle_{\text {fct }}$ (or $\{101\}\langle 10 \overline{1}\rangle_{\mathrm{bct}}$ ) in the $L 1_{0}$ martensite are close to a soft mode $\{101\}\langle 10 \overline{1}\rangle_{B 2}$. This alloy can be considered as a competitive material possessing a high-temperature shape memory effect. 


\section{REFERENCES}

1. Diagrammy sostoyanii dvoinykh metallicheskikh sistem. Spravochnik. T. 3. Kn. 1 (Phase Diagrams of Binary Metal Systems: A Handbook), Lyakishev, M.P., Ed., Moscow: Mashinostroenie, 1999, vol. 3, Book 1, pp. 359-361.

2. Adachi, K. and Wayman, C.M., Transformation behavior of nearly stoichiometric Ni-Mn alloys, Metall. Trans. A, 1985, vol. 16, pp. 1567-1579.

3. Nikolin, B.I., Mnogosloinye struktury i politipizm v metallakh i splavakh (Multilayer Structures and Polytypicism in Metals and Alloys), Kiev: Naukova Dumka, 1984.

4. Kren, E., Nagy, E., Nagy, I., Pal, L., and Szabo, P., Structures and phase transformations in the $\mathrm{Mn}-\mathrm{Ni}$ system near equiatomic concentration, J. Phys. Chem. Solids, 1968, vol. 29, pp. 101-108.

5. Tyapkin, Yu.D. and Lyasotskii, I.V., Intraphase Transformations, in Itogi nauki i tekhniki. Ser. Metallovedenie i termoobrabotka. T. 15 (Results of Science and Technique. Ser. Metal Sci. Thermal Treatment), Moscow: VINITI, 1981, vol. 15, pp. 47-110.

6. Litvinov, V.S., Bogachev, I.N., Arkhangel'skaya, A.A., and Pantsirova, E.G., Electron-microscopic study of martensite of nickel-aluminum alloy, Fiz. Met. Metalloved., 1973, vol. 36, pp. 388-393.

7. Pushin, V.G., Kondrat'ev, V.V., and Khachin, V.N., Predperekhodnye yavleniya $i$ martensitnye prevrashcheniya (Pretransition Phenomena and Martensite Transformations), Ekaterinburg: Ural. Otd. Ross. Akad. Nauk, 1998.

8. Pushin, V.G., Pavlova, S.P., and Yurchenko, L.I., Study of pretransition states and martensitic transformation in V2 Ni-Al alloys, Fiz. Met. Metalloved., 1989, vol. 67, no. 1, pp. 164-174.

9. Pushin, V.G., Yurchenko, L.I., Sokolova, A.Yu., and Ivanova, L.Yu., Premartensitic phenomena in V2 NiAl alloys: An electron microscopic, X-ray, and electron diffraction study, Phys. Met. Metallogr., 1994, vol. 78, pp. 657-665.

10. Pushin, V.G. and Kondrat'ev, V.V., Pretransition Phenomena and Martensitic Transformations, Phys. Met. Metallogr., 1994, vol. 78, pp. 497-511.

11. Pushin, V.G., Prokoshkin, S.D., Valiev, R.Z., et al., Splavy nikelida titana s pamyat'yu formy. Ch. 1. Struktura, fazovye prevrashcheniya i svoistva (Titanium Nickelide Alloys with Shape Memory. Ch. 1. Structure, Phase Transformations and Properties), Pushin, V.G., Ed., Ekaterinburg: Ural. Otd. Ross. Akad. Nauk, 2006.

12. Pushin, V.G., Alloys with a thermomechanical memory: Structure, properties and applications, Phys. Met. Metallogr., 2000, vol. 90, Suppl. 1, pp. S68-S95.

13. Pushin, V.G., Muslov, S.A., and Khachin, V.N., X-ray and electron microscopic studies of V2 compounds on the basis of TiNi, Fiz. Met. Metalloved., 1987, vol. 64, pp. 802-808.

14. Pushin, V.G., Khachin, V.N., Kondrat'ev, V.V., et al., Structure and properties of V2 compounds of titanium. I, Fiz. Met. Metalloved., 1988, vol. 66, pp. 350-358.

15. Umanskii, Ya.S., Rentgenografiya metallov (X-ray Spectroscopy of Metals), Moscow: Metallurgizdat, 1960.

Translated by T. Gapontseva 